Mr. Huskisson? I do most conscientiously, and most unequivocally, beg leave to say, there was not.

\section{Yours obediently,} Tromas Weatherile, M.D. Liverpool, Oct. 26, 1830.

\section{LETTER FROM MR. SELLS,}

\section{To the Editor of The Lancet.}

Sir,-Your liberal impartiality in observing the maxim of "Audi alternm partem," assures me that you will readily insert my short notices of two passages in Mr. Morson's defence of Mr. Bowen.

'To that of "Mr. Bowen and myself having met each other frequently,"-I have to deny it entirely, having never even seen him from the period of Mrs. Clarke's death, until after Sir A. Halliday stopped me in the street at Hampton, and said to me, "I "ve seen Bowen, it's all lies; he opened the head, and delivered the woman."

To the equivocal passage of his believing something, and about my not coming forward at the meeting or council held at Mr. Jackson's on Aug. 26th, I have to express my opinion that it never was intended I should be present, as I had no information, direct or indirect, of when it was to take place, and knew not of such meeting having occurred until two days afterwards.

I remain, Sir,

Your most obedient servant,

Kingston, Nor. 2d, 1830.

$$
\text { William Selis. }
$$

SUMMER LECTURES ON SURGEFY.

\section{To the Editor of The Lancet.}

Sir,--In your last Number of THE IANCET, in answer to your correspondent, "A Medical Student," I perceive that you are not aware that the Court of Examiners of the Royal College of Surgeons will receive a certificate of a summer course of lectures on surgery, duly delivered between the months of May and October, and including, like the winter course, not less than sixty lectures, which $I$ am now delivering, and shall recommence on the 1 st of June, 1331. I have by me a letter from the secretary of the College, in answer to one from me, dated 1st of October, stating that my summer course will be received.

I am, Sir, yours obediently, J. Evans Riadore.

17, Tavistock Square, Nov, 1st, 1830.
MOTIONS OF THE HEART.

To the Editor of ' $\mathrm{T}_{\mathrm{HE}} \mathrm{L}_{\mathrm{A}} \mathrm{Ne}$.

SIR,-In reading yesterday, in The $\mathrm{L}_{\mathrm{AN}}$ CET, your very excellent and candid review of Dr. Corrigan's opinions on the motions of the heart, and the cause of the impulse of the heart on the chest, I was struck by the fact, that both Dr. Hope and Dr. Corrigin, as well as the reviewer, in speaking of the tendency which a flexible tube has either to become straightened or still more bent upon the injection of a fluid, omitted to consider the influence of the form of the tube-I mean the shape of its cavity-or, to speak in a different manner, that they overlooked this, viz. that the injection of a fluid into a tube of flexible materials would (particu. larly if its passage through were in some measure resisted) cause the sides of the tube to assume that position in which the cavity of the tube became the greatest.

Therefore, upon the injection of a fluid into a tube of flexible materials (like the aorta), with some degree of resistance to its passage off at the other end, the tube would become either more straightened or bent than it was before the injection, according to the position of the tube when partially empty or flaccid, in relation to its position when distended to the utmost.

If you think these observations worth insertion, will you favour me by giving them a place in your Journal.

I remain yours,

H. P. L. DREW.

Thursday, October 7, 1830. 79, Gower Street.

\section{TO CORRESPONDENTS.}

'The whole of the letters requiring answers will be noticed in our next. The Index to the last volume will also be published with our succeeding Number.

A Married Medical Assistant. He cannot dispense his own medicines without being liable to the penalties in question, although he may not style himself "s A pothecary." Neither will a court of law assist him to recover debts for medicines and attendance.

The letter of Hiatus must be authenticated.

The letter of $\boldsymbol{H}$. $F$., Bristol, was mislaid, and we presume that an answer to it would not now be desired.

We have not addressed a letter to our correspondent $H$. $R$., of Leominster, because we cannot yet give him all the information he desires; but whenever the arrangements are complete, ample opportunities of becoming acquainted with them will be afforded in this Journal. 